\title{
A CRIATIVIDADE LEXICAL EM FINNEGANS WAKE E A TRADUÇÃO
}

\author{
Célia Luiza Andrade Prado
}

RESUMO: Em toda língua viva surgem criações lexicais que não passam a fazer parte da linguagem cotidiana e não são dicionarizadas: são criações literárias com propósito estilístico. O presente artigo apresenta o cotejo de algumas criações lexicais em fragmentos de Finnegans Wake, de James Joyce, com tradução de Augusto e Haroldo de Campos. Este trabalho tem o objetivo de verificar se há equivalência dos processos de criação lexical entre original e tradução e se o resultado obtido pelos tradutores confere a mesma expressividade que tem o texto original.

UNITERMOS: neologismo; criação lexical; expressividade; tradução.

ABSTRACT: In any living language there are lexical creations that arise to reach a specific goal; they are valid for a specific period and will never be incorporated into the dictionary: they are literary creations with stylistics purposes. Going through the ways of Stylistics, we compare in our paper how lexical creations in excerpts of James Joyce's Finnegans Wake were recreated in the translations of Augusto and Haroldo de Campos and analyze if the expressiveness achieved by these neologisms are the same in the source and target text.

KEYWORDS: neologism; lexical creation; expressiveness; translation.

* Mestranda na área de Estudos Linguísticos e Literários em Inglês, FFLCH-USP. 


\section{Introdução}

Traduzir James Joyce é uma ginástica com a palavra.

Haroldo de Campos

A linguagem literária difere da linguagem referencial porque, entre outros aspectos, pressupõe um efeito estético. Visando a obter tal efeito, escritores utilizam recursos estilísticos de diferentes maneiras, conferindo expressividade ao texto. São criações que não passam a fazer parte da linguagem cotidiana e não são dicionarizadas. Dentre esses autores destacamos James Joyce, que foi um hábil manipulador da língua inglesa. Em Finnegans Wake, o escritor irlandês faz uso intenso de diversos processos de composição como um "verdadeiro alquimista do léxico" (Campos, 1971:22).

Finnegans Wake é o último romance de Joyce, publicado em 1939. Em linhas gerais, trata-se da história de Humphrey Chimpden Earwicker, vulgo HCE, sua mulher, Ana Livia Plurabelle, e seus três filhos. No entanto, o enredo vai além de uma história familiar. Trata-se de uma "alegoria da queda e ressurreição da humanidade" (Campbell; Robinson, 1971:106).

O título é inspirado numa canção tradicional irlandesa, cujo protagonista, Tim Finnegan, embriagado cai de uma escada e morre. No velório (wake) alguém derruba uísque no defunto, que volta à vida e começa a dançar com os presentes. O nome Finn evoca o mais famoso gigante da Irlanda, um dos heróis guerreiros celtas. Consequentemente, o título, Finnegan, joga com a figura mítica (Finn) e com o retorno à vida de Tim Finnegan (again).

Em Finnegans Wake, cada linha apresenta uma plurissignificação instanciada pela manipulação lexical, por recursos sonoros e pela intertextualidade. De leitura considerada bastante dificil, inclusive pela fusão de outras línguas é, também, um desafio à tradução. Para traduzir obras como essa, o tradutor precisa ter a mesma habilidade do autor para recriar o texto na lingua alvo.

Este trabalho tem por objetivo verificar se há equivalência dos processos de criação lexical entre original e tradução e se o resultado obtido pelos tradutores confere a mesma expressividade que tem o texto original.

TRADTERM, 15, 2009, p. 25-40 


\section{Traduzindo Finnegans Wake}

Finnegans Wake é o tipo de obra que desafia a tradução. Trechos desse romance foram traduzidos para diversas línguas, sendo que Joyce supervisionou algumas dessas traduções, além de ter traduzido, ele próprio, para o italiano (Esteves, 1999:121). No Brasil, temos a tradução completa da obra por Donaldo Schüler, além de excertos por Paulo Leminski, Arthur Nostrovski e pelos irmãos Augusto e Haroldo de Campos, onde, aliás, se esclarece que traduzir Joyce é "um trabalho de perfeccionismo" (Campos, 1971:21).

A começar pelo título em português, Finnicius Revém, que apesar de não se relacionar com as figuras míticas acima mencionadas, apresenta o aspecto "circular" do romance: começa pelo fim (Finn) e termina pelo início (innicius); Revém abarca o sentido de retorno, da volta à vida que aconteceria no velório (wake). Também, poderia conter um rêve (sonho em francês), pois wake também significa despertar. Assim, a recriação do título representa o fim e o retorno, trazendo em si a circularidade da obra que inicia in media res, com a continuação da última linha do livro, mantendo-se dentro do mesmo campo semântico de "devaneio".

O romance revolucionário de Joyce é escrito numa linguagem que muitas vezes não parece ser inglês. "Joyce fragmentou, quebrou, desmantelou a língua inglesa [de tal maneira que] o tradutor terá também que compor um texto desmantelando sua língua" (Esteves, 199:122). Segundo Haroldo de Campos,

Ninguém, como Joyce, levou a tal extremo a minúcia artesanal da linguagem. Seu macrocosmo - seu romancerio - traz, em quase cada uma das unidades verbais que o tecem, implícito um microcosmo. (Campos, 1971:21)

A criatividade lexical, que chega a ser uma "marca registrada" de James Joyce, pode representar um obstáculo para muitos tradutores; mas para Haroldo de Campos, quanto mais intraduzivel parece um texto mais recriável será, porque "numa tradução dessa natureza não se traduz apenas o significado, traduz-se o próprio signo, ou seja, sua fisicalidade, sua materialidade mesma", o que seria "o avesso da tradução literal” (Campos, 2004:35).

TradTerm, 15, 2009, p. 25-40 
Em Finnegans Wake o enredo em si não é tão importante; associadas à história central de $\mathrm{HCE}$ e sua família, encontramos outras narrativas. Muitas são as referências a fatos míticos e históricos que "não são de fato narrados, mas sim aludidos de uma forma bastante tortuosa e enigmática". Assim, a grande "personagem" desse romance é a palavra: "palavras-valise, palavras-montagem, palavra-metáfora, palavra-ideograma" (Ibid:130), exigindo do tradutor um trabalho de recriação.

A dificuldade de tradução desses neologismos reside, primeiramente, no problema de compreensão. A não decodificação pode conduzir a diferentes leituras, comprometendo a sua recriação em outra língua. Nesse sentido, a cada leitura o tradutor poderia atribuir ao novo termo um conteúdo semântico diferente. Por isso Haroldo de Campos (1971:21) adverte que Joyce obriga o tradutor "a um retorno periódico ao texto e seus labirintos", pois sua escrita "nunca assume o aparato estático do definitivo". A tradução de Finnegans Wake, ainda segundo Campos, é "uma espécie de jogo livre e rigoroso [...] frente ao diverso feixe de possibilidades do material verbal manipulado".

\section{Fundamentação teórica}

Joyce lança mão de várias técnicas de escrita inclusive a de "quebrar palavras e compô-las em novos conjuntos, pondo em jogo várias cadeias significantes simultaneamente" (Esteves, 1991:122). Esse recurso estilístico de grande expressividade utilizado por Joyce em Finnegans Wake é semanticamente muito rico. A criatividade lexical de Joyce evidencia-se em grande parte nos cruzamentos vocabulares, processo que consiste em utilizar duas palavras para compor uma outra. Nesse tipo de criação, além do significado novo há "também o impacto provocado pelo seu caráter neológico e pelo processo por que passou. Aquilo que parecia ser um mero arranjo de significante, revela-se como um neologismo semântico e fonológico dos mais eficazes" (Barbosa, 1981:192).

O cruzamento vocabular tem recebido várias designações: palavra-valise, amálgama, palavra entrecruzada, palavra-monta-

TRADTERM, 15, 2009, p. 25-40 
gem, composto fantasia, palavra portmantea $u^{1}$, mas sempre passa pelo mesmo processo de formação: a fusão estreita de duas palavras. Robert Galisson (1991:43) ao comentar que o uso de palavra-valise na lingua corrente pode ser considerado um fenômeno recente, constata que durante séculos essas formações criadas por inúmeros escritores "ficaram encerradas nos limites estreitos da literatura e não foram mais que um epifenômeno mesmo na obra de seu criador". ${ }^{2}$

Com relação à literatura brasileira, esse recurso, segundo Nilce Sant'Anna Martins (2003:123), entrou "em voga na linguagem" no século XX, principalmente a partir do Modernismo. A manipulação do léxico por Guimarães Rosa e Mário de Andrade, por exemplo, é uma das "grandes forças da sua narrativa" (Barbosa, 1981:177).

Entretanto, Haroldo de Campos (2004:39) invoca Odorico Mendes, tradutor da Odisséia no século XIX, como sendo "o primeiro a propor e a praticar com empenho aquilo que se poderia chamar uma verdadeira teoria da tradução" por conta de seus amálgamas. E cita como bem-sucedidas as formações alidourada, criniazul, bracicândida, "tudo dentro do contexto que cria e das regras do jogo que estabeleceu" (Idem, ibidem).

O próprio Haroldo de Campos, também, lança mão desse recurso estilístico tanto em traduções quanto na criação poética. Em Galáxias, um texto com "fosforescências semânticas entre o branco do papel e o negro", no dizer de Octavio $\mathrm{Paz}^{3}$, as formações, "sobrescrevo sobrescravo em milumanoites milumapáginas" se caracterizam pela "especificidade semântica, isto é, elas vêm muitas vezes carregadas de emocionalidade" (Sandmann, 1992:58-59).

1 Expressão adotada por Lewis Carroll, empréstimo do francês (portemanteau) na lingua inglesa, que significa um tipo de alforje duplo de couro levado no cavalo contendo os pertences do cavaleiro no século XIX (Galisson, 1991:47).

2 Ils restèrent enfermés dans le cadre étroit de la littérature et ne furent qu'un épiphénomène dans l'oeuvre même de leurs créateurs (Tradução nossa).

3 A respeito dos fragmentos de Galáxias publicados em Change 4, Paris, 1970.

TradTerm, 15, 2009, p. 25-40 
Maria Aparecida Barbosa (1981:264) esclarece que "o princípio da neologia sintagmática reside na combinação de vários segmentos reconhecidos como signos distintos, autônomos. Produz-se uma nova palavra, a partir da junção de elementos mórficos já existentes na língua". Segundo Alves (1990:69), na formação do amálgama acontece "um tipo de redução, duas bases são privadas de parte de seus elementos para constituírem um novo item léxico: uma perde sua parte final e outra, sua parte inicial". Para Sandmann (1992:58), "as bases que entram na formação de nova unidade lexical, ou ao menos uma, sofrem diminuição, não sistemática ou regular, de seu corpo fônico". Martins (2003:123) descreve o processo como sendo uma "fusão de duas palavras que têm alguns fonemas comuns, os quais propiciam a soldagem".

Diante de exemplos concretos, alguns processos são fáceis de definir; todavia, entre alguns tipos de formação não há "uma fronteira nítida", sendo que as definições e conceitos dependem da perspectiva teórica adotada a respeito da unidade lexical. A distinção "se efetiva ao nível da combinatória semêmica das lexias implicadas” (Barbosa, 1981:194-5). O importante é que quaisquer que sejam os processos de descrição, todos estarão "fundamentados no princípio de união de elementos distintos para definir um tipo essencial de neologia lexical" (Guilbert, 1975:101).

Seja qual for o processo de criação lexical - amálgama, aglutinação, justaposição, palavras-valise - o resultado é um neologismo rico e expressivo por trazer a carga semântica das palavras formadoras e o inesperado da combinação. Esses neologismos são raros em discursos que não sejam literários, ou publicitários, porque sua formação é motivada por algum outro impulso - humorístico, crítico, poético - maior que a junção de significados, e diferem dos outros tipos de composição, pois têm baixa produtividade, raramente saem do universo literário para passar à língua comum.

Tais recursos estilísticos expressam de maneira inédita ideias não originais, uma visão pessoal do mundo. São formações absolutamente gratuitas, com o objetivo de satisfazer o sentimento estético do criador (Guilbert, 1975:41), cujo valor expressivo achase no contexto e motiva-se a cada leitura.

TradTerm, 15, 2009, p. 25-40 
Para Cardoso,

É o inesperado que gera estranhamento, contribuindo para que a nova unidade lexical seja responsável por mobilizar a memória, o imaginário, os desejos do receptor, conduzindo-o à percepção de outros pontos de vista sobre o mundo. (Cardoso, 2006:686)

O efeito que esse tipo de criação causa no leitor pode depender de algumas questões, tais como a sua bagagem cultural, a maior ou menor flexibilidade no uso da língua, a época em que a obra é lida. Todos esses aspectos são importantes no processo de tradução, pois o ato tradutório é, antes de qualquer coisa, um ato de leitura.

No texto de Joyce encontramos diferentes processos de criação visando à sonoridade, às associações, ao estranhamento. Em Finnegans Wake "há uma rede renhida de efeitos sonoros a ser mantida, entremeada de qüiproquós, trocadilhos, malapropismos" (Campos, 1977:22).

\section{Finnegans Wake e Finnicius Revém}

Com vistas à realização da análise, selecionamos nove excertos de Finnegans Wake que apresentam criações lexicais em confronto com a tradução para o português. Chamamos atenção para o fato de que alguns dos processos de criação lexical explorados neste trabalho nem sempre podem ser considerados

palavras-valise; no entanto são muitas vezes traduzidos por meio desse tipo de formação.

Uma vez que a proposta do trabalho é comparar o modo como os processos de criação lexical se realizam na tradução, não se pretenderá aqui discutir os diversos níveis de significação tampouco investigar as várias interpretações possíveis de tais criações. No entanto, estando cientes de que a manipulação do léxico é uma "busca da expressividade e da produção de um efeito de sentido" (Cardoso, 2006:685) e de que não se pode dissociar o aspecto formal do semântico, cada ocorrência analisada será brevemente contextualizada.

TRadTerm, 15, 2009, p. 25-40 
O corpus deste trabalho foi selecionado de Panaroma do Finnegans Wake, de autoria de Augusto e Haroldo de Campos. Essa obra apresenta 16 fragmentos do romance de Joyce, original e tradução, além de comentários sobre os excertos.

Para efeito de análise, as ocorrências selecionadas serão apresentadas lado a lado, o original e a tradução por Augusto de Campos (AC) e Haroldo de Campos (HC) - doravante, texto fonte (TF) e texto alvo (TA). As criações lexicais objetos desta análise apresentam-se em negrito. A indicação das páginas no TA referem-se ao Panaroma do Finnegans Wak, e no TF, às edições Faber $\&$ Faber (inglesa) e The Viking Press (americana) ${ }^{4}$.

As primeiras ocorrências são de um pequeno trecho, logo no início do romance, que descreve brevemente uma parte da cidade de Dublin onde há um cemitério.

\begin{tabular}{|l|l|}
\hline 1. FW & AC \\
\hline By the mausolime wall. Fimfim & Junto ao muro do mausolimo. \\
fimfim. With grand funferall. & $\begin{array}{l}\text { Fimfim fimfim. Um cortejo funébrio. } \\
\text { Fumfum fum fum. (p. 13) }\end{array}$ \\
\hline
\end{tabular}

No TF, o muro cerca o cemitério, que é uma fusão de mausoleum e lime. Lime pode ser uma fruta, uma árvore ou substância calcária presente num tipo de pedra (limestone) muito usada em edificações; por isso, parece que a última acepção é a mais adequada. No TA, o primeiro elemento desse cruzamento vocabular não oferece problema na tradução, pois há correspondência de significado e de significante. Quanto ao segundo elemento, o tradutor opta pela correspondência sonora com limo, que apesar de perder a relação com o material empregado na construção, não se distancia da imagem de um muro de cemitério tomado pela umidade.

Funeral é a mesma palavra em inglês e em português, entretanto, no TF é ao mesmo tempo funeral e divertimento: fun (divertido) for all (para todos). Vale lembrar que o funeral irlandês é tradicionalmente celebrado com bebida e cantos. No TA esse funeral é fúnebre e ébrio, remetendo à morte de Finnegan, que por causa de embriaguez morre ao cair da escada, mas que ressuscita quando alguém, no velório, acidentalmente derrama uísque sobre seu cadáver.

$4 \quad C f$ Campos, 1971:24.

TradTerm, 15, 2009, p. 25-40 
A seguir apresentamos dois trechos da descrição, ao mesmo tempo irônica e grotesca, da casa caótica do escritor Sham, figura solitária e orgulhosa.

\begin{tabular}{|c|c|}
\hline 2. $F W$ & $\mathrm{HC}$ \\
\hline $\begin{array}{l}\text { in which the soulcontracted son } \\
\text { of the secret cell groped through } \\
\text { life at the expense of the } \\
\text { taxpayers, dejected into day and } \\
\text { night with jesuit bark and bitter } \\
\text { bite, (p. 182) }\end{array}$ & $\begin{array}{l}\text { ali onde o rèubento almicontracto } \\
\text { da célula secreta tactejou vida a } \\
\text { fora a expensas dos pagataxas, } \\
\text { dejectado diasnoites a fio com } \\
\text { aladrido jesuita e sossofrida } \\
\text { murdidura, (p. } 47 \text { ) }\end{array}$ \\
\hline
\end{tabular}

Nesse excerto, soulcontracted, de alma (soul) contraída, (contracted), é traduzido por uma formação de ares eruditos por conta do primeiro elemento, almi, e da grafia arcaica de contracto. Esse adjetivo qualifica outro cruzamento vocabular, réubento, que no TF é simplesmente son (filho). No português ele é mais que um rebento; é julgado e benzido, daí sua alma contrita.

A criatividade da tradução acha-se em outras ocorrências desse mesmo trecho. Primeiramente, groped, do verbo grope, palavra dicionarizada que significa tatear transforma-se em tactejou, combinação do arcaísmo tactear com o sufixo verbal -ejar, que sugere duração, repetição (Cunha, 1980:118).

Em segundo lugar, Taxpayers, uma composição dicionarizada e de uso corrente na língua inglesa, significa contribuinte, aquele que paga os impostos. HC cria a justaposição pagataxas, com alteração da estrutura conforme o modelo de formação do português.

Consideramos a tradução um empréstimo semântico, uma vez que tax significa imposto em português, ao passo que o que chamamos de taxa é fee. O empréstimo imprime a "cor local" do texto irlandês e "o efeito de desambientação provoca um choque expressivo" (Cardoso, 2007:3).

O grupo nominal day and night, que poderia ser simplesmente dia e noite, é justaposto em diasnoites no TA, reproduzindo a técnica que Joyce utiliza em muitas outras passagens. Bark, que significa latir, passa a ser aladrido: ladrar com alarido, amplificando o som do latido nessa palavra-valise. A mordida amarga, bitter bite, ganha expressividade na tradução sossofrida murdidura com o redobro da sílaba so de sofrida, ecoando a solidão daquele que sofre, e com o cruzamento de mordida com urdidura. Esta última

TradTerm, 15, 2009, p. 25-40 
palavra, segundo Houaiss, além de ser a trama de fios, pode conter um sentido figurado de tramoia.

\begin{tabular}{|l|l|}
\hline 3. $F W$ & HC \\
\hline $\begin{array}{l}\text { longsufferings of longstanding, } \\
\text { ahs ohs oussis jas jos gias ney thaws }\end{array}$ & $\begin{array}{l}\text { longipenares de longipenantes, ahs } \\
\text { ohs ouis sis jas jos gias ohnão } \\
\text { sos, yeses and yeses and yeses } \\
\text { aguoras sins assins sinsins (p. 49) }\end{array}$ \\
\hline $\begin{array}{l}\text { p. 184) }\end{array}$
\end{tabular}

Também no fragmento acima, a criatividade do tradutor excede a do autor. No TF, a supressão do hífen nos termos justapostos e dicionarizados - long-suffering e long-standing (em linhas gerais: suportando resignadamente o sofrimento por longo tempo), que não se pode considerar um processo "radical" de criação lexical, resulta em unidades maiores, cuja força reside na imagem gráfica. No TA, a formação de duas palavras-valise constituídas do advérbio "longe" e da nominalização do verbo "penar" busca manter o volume correspondente. A redundância de "penares dos penantes, ou seja, aqueles que penam" reforça a ideia de sofrimento infinito.

Os trechos abaixo são do capítulo VIII do primeiro livro no momento em que as lavadeiras comentam a vida de Ana Livia Plurabelle.

\begin{tabular}{|c|c|}
\hline 4. $F W$ & $\mathrm{AC}$ \\
\hline $\begin{array}{l}\text { She was just a young thin pale soft } \\
\text { shy slim slip of a thing then, } \\
\text { sauntering, by silvamoonlake } \\
\text { (p. 202) }\end{array}$ & $\begin{array}{l}\text { Ela era só uma tímida tênue fina } \\
\text { meiga mini mima miga duma } \\
\text { coisinha saltiritando, } \\
\text { silvalunágua (p. } 57 \text { ) }\end{array}$ \\
\hline
\end{tabular}

A primeira ocorrência no $\mathrm{TF}$, apesar de não ser qualquer tipo de neologismo na língua inglesa - trata-se do particípio presente de um verbo (saunter) que significa caminhar de maneira relaxada e lenta -, é traduzida com a fusão de dois verbos: saltar e tiritar. Saltiritando reforça a imagem frágil e trêmula da mulher que, numa noite de luar, passa pelo lago. Na tradução da justaposição silvamoonlake mantém-se a lua (moon), em sua forma latina luna, e o lago (lake) é substituído pelo hiperônimo água. No $\mathrm{TF}$, o elemento silva possui duas acepções em inglês: a primeira silver do germânico seolfor, que significa prata, e a segunda sylvian ou silvan, do latim, relativo a bosque. No TA perde-se o primeiro significado, pois em português silva tem somente a origem latina; entretanto, a imagem prateada da lua refletida na água permanece em lunágua.

TradTerm, 15, 2009, p. 25-40 
Da cena do banho de Ana Livia analisaremos as criações lexicais dos trechos cinco e seis:

\begin{tabular}{|l|l|}
\hline $5 . F W$ & HC \\
\hline $\begin{array}{l}\text { Then, mothernaked, she sampood } \\
\text { herself with galawater (p. 206-7) }\end{array}$ & $\begin{array}{l}\text { Então, madrenua, ela ensampunou-se } \\
\text { com galágua (p. 59) }\end{array}$ \\
\hline
\end{tabular}

Nesse fragmento, a sonoridade é bastante evocativa. Mothernaked, além de ser a mãe nua, madrenua, evoca, pelo som, a mãe natureza, mother nature, que circunda o local do banho, aspecto que se perde na tradução.

Ensampunou-se traz em sua formação ensaboar e ensampar, que tem o sentido figurado de enfeitiçar, mantendo a sonoridade de sampood (do dicionarizado shampooed). Para ensaboar-se é preciso água. A justaposição do determinante gala e do determinado água evidencia o aspecto ritualístico desse banho, uma vez que em ambas as línguas gala significa ocasião solene.

\begin{tabular}{|l|l|}
\hline $6 . F W$ & HC \\
\hline $\begin{array}{l}\text { The cock striking mine, [...] there's } \\
\text { Zambosy waiting for Me! (p. 206-7) }\end{array}$ & $\begin{array}{l}\text { O riológio tocantina a hora falidica, } \\
\text { [..] tem um Zé zambezando à minha } \\
\text { espera. (p. 59) }\end{array}$ \\
\hline
\end{tabular}

A primeira palavra do romance é riverrun (riocorrente). Segundo Haroldo de Campos (1971:89), "numerosos nomes de rios cerca de 500 - estão camuflados semanticamente no texto, o que obrigou os tradutores, num jogo de perde-ganha, a compensarem, com as variantes cabiveis, os trocadilhos fluviais".

No trecho acima parece que o tradutor buscou essa compensação, pois há duas associações ao rio no TA - zambezsando e riológio - em contraste com uma no TF - Zambosy, numa alusão ao Rio Zambeze. No TA, o rio é personificado em Zé, um dos mais comuns apelidos brasileiros, remetendo o texto às referências brasileiras. O presente do participio zambezando, aliado aos sons sibilitantes produzidos pela aliteração da letra $z$, reforça a imagem do rio que corre (riverrrun).

Joyce faz um trocadilho com the clock striking nine (o relógio soa nove horas) que resulta em the cock striking mine. Cock tem muitos significados, mas ressaltaremos dois que parecem ter mais relação com o texto: galo, que canta o raiar do dia, e o órgão genital

TRADTERM, 15, 2009, p. 25-40 
masculino, cujo sentido sexual é reforçado por striking mine (golpeando o meu). A tradução joga com o erótico em hora falídica, cruzamento de falo com fatídica, compensando a perda da ambiguidade de cock.

Do Livro II, este fragmento descreve as brincadeiras das crianças na rua ao entardecer:

\begin{tabular}{|c|c|}
\hline 7. $F W$ & $\mathrm{HC}$ \\
\hline $\begin{array}{l}\text { We are circumveiloped by } \\
\text { obscuritads. }[\ldots] \text { The swayful } \\
\text { pathways of the dragonfly spider } \\
\text { stay still in reedery. (p. 244) }\end{array}$ & $\begin{array}{llr}\text { Somos circunvelopardos } & \text { pela } \\
\text { urubuscuridade. }[\ldots] & \text { Veredas, } \\
\text { volúvias da libéluaranha } & \text { pousam } \\
\text { paz nos juncos. (p. 67) } & \end{array}$ \\
\hline
\end{tabular}

O anteposto latino circum- (em volta de) é encontrado na composição do inglês e do português. No TF, a esse prefixo juntamse os verbos veil (cobrir com véu), e envelope (envolver, encobrir) com um resultado absolutamente redundante.

No pequeno trecho analisado há mais referências a animais no TA que no TF. As ocorrências circunvelopardos não só abrigam envelopados mas também leopardos, e urubuscuridade, uma escuridão da cor de urubus. Para a tradução do vernacular dragonfly (libélula) spider (aranha) a palavra-valise libéluaranha contém dois insetos que envolvem a lua que não brilha nessa obscuridade. Parece ser novamente uma compensação de perdas na tradução em outros trechos, pois para os tradutores (Campos, 1971:92), toda "a cena tem uma coloratura zoomórfica".

Os dois excertos abaixo são do monólogo da mulher lamentando o abandono do marido, que vai trocá-la por uma mulher mais nova.

\begin{tabular}{|c|c|}
\hline 8. $F W$ & $\mathrm{HC}$ \\
\hline $\begin{array}{l}\text { Yes, you're changing, sonhusband, } \\
\text { and you're turning, I can feel you, for } \\
\text { a daughterwife from the hills again. } \\
\text { Imlamaya. And she is coming. } \\
\text { Swimming in my hindmoist. [...] I } \\
\text { can see meself among them, } \\
\text { allaniuvia pulchrabelled. (p. } 627-8 \text { ) }\end{array}$ & $\begin{array}{l}\text { Sim, você está mudando, filhespôso, } \\
\text { está se voltando, posso senti-lo, para } \\
\text { uma filhespôsa das montanhas de } \\
\text { nôvo. Imlamaya. Ei-la que vem. } \\
\text { Nadando em meu nebulonge. [...] } \\
\text { Posso ver-me entre elas, allaniúvia } \\
\text { pulchrabella. (p. } 75 \text { ) }\end{array}$ \\
\hline
\end{tabular}

Os cruzamentos vocabulares sonhusband / filhespôso e daughterwife / filhespôsa evidenciam a complexidade do relacionamento homem/mulher que parece ser tanto marital quanto fraternal.

TradTerm, 15, 2009, p. 25-40 
Novamente o erótico transparece na ambiguidade de hindmoist. Essa composição contém hind, que significa a parte posterior da coxa, e moist, úmido, mas pela sonoridade kind aproxima-se de hindmost (o último, o mais atrás). A tradução nebulonge recupera, com longe, este último significado acrescentando-se a ele o anteposto latino nebul-, de nuvem/névoa, acentuando, também pela sonoridade, a impressão de distância e de falta de clareza. Nebulonge, transformado em substantivo, remete ao adjetivo nebuloso. O cruzamento allanuvia joga com o nome de Ana Livia e o adjetivo nuvioso, também do latim nubilosus. Plurabella, o sobrenome da protagonista, que é "pluralmente bela", ressoa no redobro semântico da composição formada pelas palavras latinas sinônimas pulchra e bellus.

\begin{tabular}{|l|l|}
\hline 9. $F W$ & HC \\
\hline And it's old and old it's sad and old & E é velha e velha é triste e velha é \\
it's sad and weary I go back to you, triste e em tédio que eu volto a ti, frio \\
my cold father, my cold mad father, \\
pai, meu frio frenético pai, meu frio \\
my cold mad feary father, till the \\
near sight of the mere size of him, \\
frenético feerivel pai, até que a pura \\
vista da mera forma dêle, as láguas e \\
moananoaning, makes me seasilt \\
saltsick and I rush, my only, into \\
lackas dêle, lamamentando, me \\
four arms. (p. 627-8) & $\begin{array}{l}\text { lance, oh único, em teus braços. (p. } \\
77)\end{array}$ \\
\hline
\end{tabular}

Essa passagem joga com uma rede de efeitos sonoros, que se verifica tanto no TF quanto no TA, como força expressiva. A aliteração do $f$, por exemplo, em feary father é reproduzida em frio frenético feerivel pai. No entanto, uma vez que o trabalho não tem como objetivo verificar a sonoridade como força expressiva, a análise se aterá às criações lexicais. Assim, feary uma composição do substantivo fear (medo) mais o sufixo formador de adjetivo -y, rompe com o bloqueio gerando estranhamento, pois o adjetivo lexicalizado para aquele que causa medo é fearsome. No TA, o correspondente a essa formação é o cruzamento vocabular feerivel. Um pai que em inglês é frio (cold) e louco ( $\mathrm{mad}$ ), em português é um pai terrivel e feérico, pertencente ao mundo da fantasia.

A ocorrência moyles - alteração gráfica de miles (milhas) resulta numa sutil mudança fonética com o intuito, talvez, de evocar uma fala específica. Tal criação é traduzida pelo cruzamento láguas - léguas + águas - novamente fazendo alusão aos "trocadilhos fluviais" de Joyce.

TradTerm, 15, 2009, p. 25-40 
O tom de lamento provocado pelo longo período, pela repetição de palavras, pelo ritmo e pelo potencial expressivo dos fonemas é reforçado pelo redobro de sílabas em moananoaning, do vernacular moaning (gemendo, lamentando), produzindo efeito onomatopaico de grande expressividade, porque existe a correlação som-ideia. No TA, correspondente a esse processo de reduplicação, há a palavravalise lamamentando, que encerra no lamento o verbo amar e amamentar, numa alusão ao relacionamento amoroso e maternal.

O último item a ser analisado, seasilt saltsick, parece ser a paródia de alguma expressão conhecida. O que se nota, à primeira vista, é uma troca dos elementos desses substantivos justapostos. Dicionarizados, temos seasick (estado de enjoo provocado pelo balanço do barco), salt (sal) e silt (sedimento). Além de jogar com a sonoridade, Joyce gera o inesperado, pela ruptura da formação conhecida por meio de duas composições inéditas.

No TA, maremal lamasal não parte de qualquer justaposição vernacular, como o inglês seasick, mas de palavras isoladas: mar, mal, lama e sal. O efeito se dá pela aliteração do $m$ e do $l$, pelo jogo sonoro com lamaçal e pela formação de dois cruzamentos absolutamente inéditos. Vale notar, na tradução, que os elementos são "destrocados": o marjunta-se ao mal e a lama ao sal.

O efeito do trocadilho não está nos vocábulos isoladamente. Faz parte de uma rede de significados externos e internos à obra e, para traduzi-lo, é preciso conhecê-lo. A tradução do trocadilho seria, assim, uma criação paralela por meio da reconstrução dos jogos verbais.

\section{Considerações Finais}

Conforme já explicitado, o objetivo deste trabalho não é discutir os diversos níveis de significação nem investigar o motivo de tais criações, mas de verificar de que maneira pode-se traduzir os diversos procedimentos de criação lexical de efeito estilístico. Há vários outros aspectos que podem ser explorados numa análise desse mesmo texto. Este trabalho, devido às restrições impostas pela extensão do artigo, está longe de repassar todos os recursos de criação lexical utilizados por Joyce e suas respectivas traduções por Augusto e Haroldo de Campos.

TradTerm, 15, 2009, p. 25-40 
Nas ocorrências analisadas, pudemos observar que nem sempre os processos de criação lexical no TF são os mesmos recriados no TA, frequentemente impostos pela particularidade de cada língua. No entanto, é procedimento usual no processo tradutório que quando ocorre uma perda em algum ponto da tradução compensase em outro. Segundo Esteves (1999:134), seria esse procedimento de compensações, que faz o efeito de criação de sentido incidir não exatamente nos mesmos pontos e não necessariamente com as mesmas referências. Nesse sentido, Arthur Nestrovski afirma que

A perda ocasional de um elemento em um ponto da tradução pode ser compensada por seu aparecimento em algum outro ponto adequado, e é característico do texto de Joyce o fato de que sempre haverá algum outro ponto adequado. (Nestrovski, apud Esteves, 1999:134)

A tradução de Finnegans Wake é mais que uma recriação: é uma criação paralela. Haroldo de Campos (1971:21) atesta que esse trabalho "exige do tradutor um esforço paralelo de reinvenção", pois cada palavra transcende o seu significado denotativo criando "uma espécie de espelho-instante da obra toda".

\section{Referências bibliográficas}

ALVES, Ieda Maria (1990) Neologismo: criação lexical. São Paulo: Ática.

BARBOSA, M. A. (1981) Produção e criatividade: processo de neologismos. São Paulo: Global.

CALDAS AULETE (1925) Diccionário Contemporâneo da Língua Portuguesa. Lisboa: Parceria Antonio Maria Pereira.

CAMPBELL, Joseph; ROBINSON, Henry Morton (1971) Introdução a um assunto estranho (trad. Augusto de Campos). In: CAMPOS, A.; CAMPOS, H. Panatoma de Finnegans Wake. São Paulo: Perspectiva. CAMPOS, Haroldo de (2004) Metalinguagem e outras metas. São Paulo:

Perspectiva, $4^{\mathrm{a}}$ ed.

(2004) Galáxias. São Paulo: Editora 34, $2^{\text {a }}$ ed.

CAMPOS, Augusto e Haroldo (1971) Panaroma do Finnegans Wake. São Paulo: Perspectiva.

TradTERm, 15, 2009, p. 25-40 
CARDOSO, Elis de Almeida (2006) Rompimento do bloqueio lexical: expressividade e produção de sentido. Estudos Lingüísticos $X X X V$. São Carlos: pp. 685-693, disponível em www.gel.org.br.

(2007) A expressividade dos estrangeirismos na poesia de Carlos Drummond de Andrade. Dominio de linguagem. Revista Eletrônica de Lingüística. Ano 1, n. 1.

CUNHA, Celso Ferreira (1980) Gramática da língua portuguesa. Rio de Janeiro: FENAME.

ESTEVES, Lenita Maria Rimoli (1999) A (im)possivel tradução de Finnegans Wake: uma investigação psicanalítica. Tese de Doutorado em Linguística. Campinas: Instituto de Estudos da Linguagem - Universidade Estadual de Campinas.

GALISSON, Robert (1991) De la langue à la culture par les mots. Paris: CLE.

GUILBERT, Louis (1975) La creativié lexicale. Paris: Librairie Larousse. HOUAISS, Antonio (2004) Dicionário da língua portuguesa. Rio de Janeiro: Objetiva.

MARTINS, Nilce Sant'Anna (2003) Introdução à estilística. São Paulo: T.A.Queiroz, $3^{\mathrm{a}}$ ed.

SANDMANN, Antônio José (1992) Morfologia lexical. São Paulo: Contexto.

6The New Oxford Dictionary of English. Oxford: Clarendon Press, 1998.

TRADTERM, 15, 2009, p. 25-40 